\title{
PENDAMPINGAN TATA KELOLA ADMINISTARASI PERSONALIA DI SMK KARSA MULIA KOTA PALANGKA RAYA
}

\author{
*Musyarapah, Khadijah, Nurfitria Oktavia, Aulia Afifa \\ IAIN Palangka Raya \\ musyarapah@iain-palangkaraya.ac.id
}

\begin{abstract}
Abstrak:
Artikel ini melaporkan hasil pengabdian kepada masyarakat mengenai pemberian materi tentang tata kelola adminitrasi personalia di SMK Karsa Mulia Kota Palangka Raya, karena di antara kendala yang dihadapi pihak manajemen sekolah SMK Karsa Mulia dalam pengembangan lembaga adalah terkait dengan persoalan administrai personalia (Sumber Daya Manusia). Kegiatan pendampingan yang akan dilakukan secara kolaboratif antara dosen dan mahasiswa prodi MMPI Pascasarjana IAIN Palangka Raya menjadi sangat relevan dan penting. Adapun tujuan kegiatan ini adalah untuk memberikan pendampingan tata kelola administrasi personalia. Kegiatan ini mendapatkan respon positif dan antusias dari para pegawai SMK Karsa Mulia. Pengabdian kepada masyarakat ini memperoleh hasil diskusi yang mana masih banyak yang perlu diperbaiki dalam sistem pengelolaan administrasi personalia di SMK Karsa Mulia kota Palangka Raya. Kegiatan pengabdian seperti ini dapat dilakukan secara rutin baik di lokasi yang sama maupun di lokasi yang berbeda dengan sasaran masyarakat yang benar-benar membutuhkan pelayanan dalam hal administrasi dan manajemen terlebih lagi kampus Pascaarjana IAIN Palangka Raya memiliki Program Studi Magister Manajemen Pendidikan Islam yang dalam hal ini juga termasuk dalam cakupan manajemen pendidikan.
\end{abstract}

Kata kunci: pendampingan, tata kelola, administrasi personalia, pengabdian kepada masyarakat

\section{Pendahuluan}

Tri Dharma Perguruan Tinggi, khususnya dharma pengabdian kepada masyarakat bagi dosen berkolaborasi dengan mahasiswa prodi MMPI sengaja dirancang dan diarahkan ke masyarakat sekolah tingkat menengah atas yakni di SMK Karsa Mulia Kota Palangka Raya dengan maksud mensosialisasikan visi, misi, sasaran dan tujuan program studi MMPI, transformasi pengetahuan dan keterampilan akademis tata kelola administrasi personalia di sekolah tersebut.

Rencana ini, sesungguhnya mendasarkan pada hasil beberapa kali kunjungan calon pengabdi. Setelah dilakukan identifikasi persoalan terkait dengan persoalan tata kelola administrasi personalia. Umumnya masih kurang mendapatkan perhatian optimal dari pihak manajemen sekolah. Ketidak optimalan dalam hal ini, terlihat misalnya; ketidakadaan dokumen data hasil analisa kebutuhan personalia, arsip dan rincian dokumen setiap mata kegiatan tata kelola administrasi personalia. Sehingga, bisa jadi bahwa tata kelola dimaksud dapat dinyatakan belum tertib, padahal tertib pengadministrasian pesonalia merupakan bagian kebutuhan sekolah. Untuk itu, memerlukan pembenahan secara terus menerus. 
Musyarapah : Pendamoingan Tata Kelola Administrasi Pesrsonalia di SMK Karsa Mulia Kota Palangka Raya

Kegiatan pendampingan yang akan dilakukan secara kolaboratif antara dosen dan mahasiswa prodi MMPI Pascasarjana IAIN Palangka menjadi sangat relevan dan penting, tentu dengan maksud untuk ikut membantu tertibnya pengelolaan adminstrasi personalia di SMK Karsa Mulia Kota Palangka Raya, yang secara bertahap akhirnya bisa sesuai dengan teori dan praktek-praktek manajerial pada domain personalia menurut manajemen personalia, yang baik dan benar.

Sesuai disiplin keilmuan, keahlian dan kompetensi yang dikembangkan oleh program studi MMPI Pascasarjana IAIN Palangka Raya, yakni ilmu-ilmu dasar manajemen, manajemen pendidikan, dan praktek-praktek manajerial yang terbingkai dalam Al-Qur`an dan Hadist Rasul, yang referensi aslinya bertuliskan menggunakan bahasa Arab dan Inggris, maka pendampingan ini, satu sisi dosen-dosen dan mahasiswa prodi MMPI bisa mengaplikasikan teori-teori manajemen modern terkait tata kelola administrasi personalia di sekolah yang menjadi bagian kajian di prodi tersebut. Sisi lain, sekaligus bermaksud ikut membenahi tata kelola dimaksud, yang diduga belum baik dan benar. Sehingga kegiatan pendampingan yang akan dilakukan oleh dosen dan mahasiswa prodi MMPI dalam hal tata kelola administrasi personalia di SMK Karsa Mulia Kota Palangka Raya sangat niscaya dan akan berdampak positif terhadap tertibnya tata kelola yang sesuai dengan standar minimal sistim tata kelola administrasi secara umum, dan khususnya tata kelola administrasi personalia di SMK Karsa Mulia Kota Palangka Raya.

Sekolah yang dipilih untuk kegiatan pengabdian dosen dan mahasiswa prodi MMPI adalah SMK Karsa Mulia Palangka Raya, yang beralamat di Jalan G. Obos Km. 5 No. 130 Kota Palangka Raya. Dipilihnya SMK Karsa Mulia Kota Palangka Raya dengan pertimbangan, di antaranya sebagai berikut :

a. SMK Karsa Mulia Kota Palangka Raya berstatus sekolah swasta, yang dari sisi budgeting mengandalkan partisipasi orang tua peserta didik dan itupun sangat terbatas, sehingga akan berpengaruh negatif pada tata kelola administrasi personalia yang baik dan benar.

b. Umumnya, pejabat struktural, guru dan tenaga-tenaga kependidikan di SMK Karsa Mulia Kota Palangka Raya belum semuanya mengikuti pelatihan, pendampingan, workshop dan atau seminar tata kelola administrasi personalia yang baik dan benar.

c. Adanya keunikan yang terjadi pada praktek-praktek manajerial pimpinan dan tenaga kependidikan, misalnya tidak memiliki perencanaan dalam manajemen personalia Al-Khidma: Jurnal Pengabdian Masyarakat Vol 1 No 2 Oktober 2021-Maret 2022 
Musyarapah : Pendamoingan Tata Kelola Administrasi Pesrsonalia di SMK Karsa Mulia Kota Palangka Raya

berbasis pada hasil analisis kebutuhan seberapa banyak personalia yang harus diterima di SMK Karsa Mulia Kota Palangka Raya.

d. Guru dan tenaga-tenaga kependidikan di SMK Karsa Mulia Kota Palangka Raya masih memerlukan bimbingan dan pedampingan dalam hal tata kelola administrasi personalia yang baik dan benar.

Mencermati dasar pemikiran tersebut di atas, maka bisa dipahamkan bahwa pengabdian masyarakat melalui kegiatan pendampingan tata kelola administrasi personalia di SMK Karsa Mulia Kota Palangka Raya serta sosialisasi visi, misi, sasaran dan tujuan program studi MMPI, publikasi dan promosi kepada pejabat struktural, orang tua, guru-guru dan masyarakat, stakeholders, jajaran pemerintahan/swasta dan masyarakat luas adalah mutlak segera dilaksanakan.

\section{KAJIAN TEORITIS}

\section{A. Konsep Administrasi Personalia}

Secara sederhana administrasi berasal dari kata Latin "ad" dan "ministro". Ad mempunyai arti "kepada" dan ministro berarti "melayani". Secara bebas dapat diartikan administrasi itu merupakan pelayanan atau pengabdian terhadap subyektertentu. ${ }^{1}$ Administrasi dalam arti sempit adalah kegiatan yang meliputi catatmencatat, surat-menyurat, pembukuan ringan, ketik-mengetik, agenda, dansebagainya yang bersifat teknis ketatausahaan. Namun administrasi dalam arti luas adalah seluruh proses kerja sama antara dua orang atau lebih dalam mencapai tujuandengan memanfaatkan sarana prasarana tertentu. ${ }^{2}$

Personalia sekolah dalam arti luas adalah meliputi guru, murid, dan pegawai. ${ }^{3}$ Namun lebih sering digunakan untuk menyebutkan suatu golongan atau organisasi seperti pendidik, pegawai tata usaha, penjaga sekolah dan lainnya yang merupakananggota organisasi dan bertanggung jawab untuk tercapainya tujuan yang sudah ditentukan.

Secara konsep personalia ditangani oleh para manajer agar aktivitas mereka dapat dipertahankan dan semakin meningkat. Para manajer akan membina mereka, berusaha mewujudkan antar hubungan yang baik, menilai dan mempromosik

\footnotetext{
${ }^{1}$ Daryanto, Administrasi Pendidikan, (Jakarta: Rineka Cipta, 2001), hlm. 1.

${ }^{2}$ Rusmaini, Ilmu Pendidikan, (Palembang: Grafindo Telindo Press, 2014), hlm. 100.

${ }^{3}$ Moh. Rifa'i, Administrasi Pendidikan, (Bandung: Jemmars, 1984), hlm.110. Al-Khidma: Jurnal Pengabdian Masyarakat Vol 1 No 2 Oktober 2021-Maret 2022
} 
Musyarapah : Pendamoingan Tata Kelola Administrasi Pesrsonalia di SMK Karsa Mulia Kota Palangka Raya

an mereka, dan berupaya meningkatkan kesejahteraan mereka, bukan hanya itu yangmenyangkut aspek personalia dimaulai dari merencanakan, merekrut, menyeleksi,meneliti, untuk perbaikan dan sebagainya smpai dengan memberhentikan ataumemberi pensiun kepada para petugas. ${ }^{4}$

Dari pengertian di atas, maka administrasi personalia dapat dipahami sebagai salah satu cabang admninistrasi yang terfokus pada pengelolaan karyawan di sebuah lembaga dalam hal ini yang terfokus pada administrasi tenaga pendidik dan kependidikan di lembaga pendidikan.

\section{B. Bidang Layanan Administrasi Personalia}

Administrasi personalia pendidikan memiliki beberapa bidang cakupan, di antaranya yaitu:

1. Administrasi personalia bagian tata usaha (TU)

2. Administrasi personalia bidang kepegawaian dan guru

3. Administrasi personalia bidang murid/siswa

\section{Proses Administrasi Personalia}

Secara umum, proses administrasi personalia membicarakan tentang perencaan, pengembangan, antar hubungan personalia, penilaian dan promosi, kesejahteraan, hingga penelitian personalia. ${ }^{5}$ Proses administrasi personalia yang dimaksud di sni adalah kegiatan-kegiatan yang dilakukan untuk mengolala personalia yang ada di lembaga pendidikan. Proses-pross tersebut, yaitu:

1. Rencana pengadaan personel

- Analisis jabatan

- Inventarisasi personel

- Pengadaan personel

2. Penataan, pengangkatan dan penempatan calon pegawai/personel

- Penerimaan pegawai/guru

- Penempatan pegawai/guru

- Penghasilan/gaji guru/pegawai

3. Kenaikan pangkat, ujian dinas dan angka kredit bagi kenaikan jabatan fungsional

\footnotetext{
${ }^{4}$ Made Pidarta, Manajemen Pendidikan Indonesia, (Jakarta : PT Rineka Cipta, 2004), hlm.108.

${ }^{5}$ Made Pidarta, op. cit., hlm. 111.
}

Al-Khidma: Jurnal Pengabdian Masyarakat Vol 1 No 2 Oktober 2021-Maret 2022 
Musyarapah : Pendamoingan Tata Kelola Administrasi Pesrsonalia di SMK Karsa Mulia Kota Palangka Raya

- Kenaikan pangkat regular

- Kenaikan pangkat pilihan

- Kenaikan pangkat istimewa

- Kenaikan pangkat pengabdian 6

4. Pengembangan karir dan peningkatan mutu tenaga kependidikan

- Pentingnya pengembangan karir

- Aspek yang perlu diperhatikan dalam pengembangan karir

- Moral kerja dan produktivitas kerja

- Kesejahteraan pegawai

- Pemindahan, pemberhentian dan pension

- Kode etik jabatan guru

Kegiatan-kegiatan tersebut harus dilakukan dengan baik, disiplin dan sesuai dengan ketetapan sehingga ke depannya administrasi personalia dapat berjalan dengan baik dan akan meningkatkan kualitas pendidikan Indonesia.

\section{HASIL DAN PEMBAHASAN}

Pengelolaan administrasi adalah suatu kewajiban yang harus dilakukan demi tercapainya sebuah tujuan dengan baik dan terstruktur, Jika pengelolaan administrai itu baik maka akan baik pula penyelenggaraan sistem pendidikan lainnya.

Pendampingan tata kelola administrasi yang dilaksanakan di SMK Karsa Mulya Kota Palangka Raya dimulai dengan pemberian materi dan diskusi kemudian dilanjutkan pendampingan dengan menggunakan media komputer/laptop. Peserta dalam pendampingan ini adalah semua Guru di SMK Karsa Mulya yang berjumlah dua puluh orang. Pendampingan dilakukan sebanyak sembilan kali pertemuan dengan total waktu pertemuan adalah dua puluh tujuh jam.

Pada awal pertemuan, terlebih dahulu dilakukan sosialisasi tentang adminitrasi pemerintahan sesuai Peraturan Menteri Dalam Negeri Republik Indonesia Nomor 47 Tahun 2016. Saat sosialisasi ini menjelaskan betapa pentingnya administrasi dalam rangka tertibnya sebuah perencanaan untuk mencapai tujuan. Pengelolaan administrasi di SMK Karsa Mulya yang terkait dengan personalia perlu adanya bimbingan dan

\footnotetext{
${ }^{6}$ Ary H. Gunawan, Administrasi Sekolah, (Jakarta: PT Rineka Cipta, 2002), hlm. 33.
} 
Musyarapah : Pendamoingan Tata Kelola Administrasi Pesrsonalia di SMK Karsa Mulia Kota Palangka Raya

pedampingan dalam hal tata kelola yang baik dan benar dengan tujuan membuat tata kelola administrasi menjadi efektif dan benar.

Sebelum melakukan pendampingan tata kelola terlebih dahulu dilakukan sosialisasi tentang pengelolaan admnistrasi. Kemudian dilanjutkan dengan pendampingan sebanyak Sembilan kali pertemuan dengan metode ceramah, studi kasus dan diskusi bersama para peserta yaitu semua karyawan yang ada di SMK Karsa Mulya. Materi yang diberikan tentang tata kelola administrasi pendidikan, fungsi manajemen administrasi, admnisitrasi personalia dan keuangan, dengan menghadirkan pemateri yang handal dan profesional di bidangnya kemudian berkolaborasi bersama mahasiswimahasiswi dari Pascasarjana IAIN Palanga Raya program studi Magister Manajemen Pendidikan Islam (MMPI).

Dilihat dari diskusi yang berlangsung bahwa dalam tata kelola administrasi di SMK Karsa Mulya perlu adanya pendampingan dan pengaturan secara efektif mengingat dalam masa pandemi ada begitu banyak data dan pengontrolan terhadap guru maupun siswa yang masih kurang efektif yang secara tidak langsung berpengaruh terhadap pencapaian visi dan misi sekolah. Kurangnya analisis dalam perencanaan kerja membuat hasil yang akan dicapai belum maksimal. Begitupun dengan pelatihan, pendampingan dan workshop yang masih kurang dilaksanakan sehingga berdampak pada berkembangnya potensi para guru yang secara tidak langsung berpengaruh pada pengelolaan sekolah itu sendiri.

Pengabdian masyarakat di sekolah SMK Karsa Mulya berlangsung selama sembilan hari dan mendapat respon yang baik dari kepala sekolah dan guru terlihat dari keikutsertaan dan keaktifan mereka selama pelatihan dan pendampingan berlangsung. Setelah melakukan sosialisasi, pelatihan, pendampingan dan diskusi serta pemberian saran, motivasi juga pendapat terkait dengan tata kelola administrasi di SMK Karsa Mulya, hal tersebut menjadikan gambaran kepada kepala sekolah dan para guru untuk perbaikan tata kelola admnistrasi personalia agar lebih baik dan efektif lagi kedepannya.

\section{Penutup Dan Saran}

\section{Penutup}

Kegiatan pengabdian kepada masyarakat mengenai pemberian materi dan pendampingan tentang tata kelola administrasi personalia yang baik di SMK Karsa 
Musyarapah : Pendamoingan Tata Kelola Administrasi Pesrsonalia di SMK Karsa Mulia Kota Palangka Raya

Mulya telah terlaksana dengan baik dan lancar. Kegiatan pengabdian kepada masyarakat mendapatkan respon yang antusias dari guru dan karyawan di SMK Karsa Mulya kota Palangka Raya. Dari pengabdian masyarakat ini telah diperoleh hasil diskusi yang mana masih memerlukan banyak perbaikan dalam sistem pengelolaan administrasi personalia di SMK Karsa Mulya terutama dalam hal rekrutmen tenaga pendidik dan kependidikan. Kegiatan pengabdian seperti ini dapat dilakukan secara rutin baik di lokasi yang sama maupun di lokasi yang berbeda dengan sasaran masyarakat yang benar-benar membutuhkan pelayanan dalam hal administrasi personalia.

\section{Rekomendasi}

Berdasarkan evaluasi yang dilakukan pada kegiatan pengabdian kepada masyarakat ini, maka rekomendasi yang diajukan yaitu, terkait dengan tata kelola administrasi personalia perlu adanya SOP yang dilaksanakan secara baik dan benar. Kegiatan serupa juga hendaknya bisa dilaksanakan secara kontinyu untuk meningkatkan pengetahuan dan keterampilan tenaga pendidik dan kependidikan di SMK Karsa Mulya agar terjadi peningkatan mengenai tata kelola administrasi personalia serta perlu diadakan kerjasama dengan instansi yang memiliki pengalaman dalam bidang administrasi atau manajemen di lembaga pendidikan.

\section{DAFTAR PUSTAKA}

Asnawir. Administrasi Pendidikan. Padang: IAIN IB PRESS, 2005.

Daryanto. Administrasi Pendidikan. Jakarta: Rineka Cipta, 2001.

Gunawan, Ary. H. Administrasi Sekolah dan Administrasi Mikro. Jakarta:Rineka Cipta, 1996.

Handoko , T Hani. Manajemen Personalia dan Sumber Daya Manusia, Yogyakarta: BPFE, 1994.

. Manajemen Personalia dan Sumber Daya Manusia, Yogyakarta: BPFE Yogyakarta, 2001.

Hasibuan, Malayu S.P. Organisasi dan Motivasi, Jakarta: Bumi Aksara, 1996. . Manajemen Sumber Daya Manusia, Jakarta: PT. Bumi Aksara, 2008.

Kamus Umum Bahasa Indonesia, 1976.

2001 Lieke, E.M. Pengaruh Kompensasi dan Motivasi Kerja terhadap Komitmen Organisasi di Organisasi Pendidikan Islam X, Jurnal Gunadarma Moekizat, Manajemen Tenaga Kerja dan Hubungan Kerja, Bandung: Pioner, 1999.

Nitisemito, Alex S. Manajemen Personalia, Jakarta: Ghalia Indonesia,1991. 
Musyarapah : Pendamoingan Tata Kelola Administrasi Pesrsonalia di SMK Karsa Mulia Kota Palangka Raya

Notoatmodjo, Soekidjo. Pengembangan Sumber DayaManusia, Jakarta: Rineke Cipta, 2003.

Panggabean, Mutiara S. Manajemen Sumber Daya Manusia, Bogor: Ghalia Indonesia, 2004.

Pidarta, Made. Manajemen Pendidikan Indonesia. Jakarta : PT RinekaCipta, 2004.

Purwanto, Ngalim. Administrasi Pendidikan. Jakarta: Mutiara Press, 1987.

Rifa'i, Moh. Administrasi Pendidikan. Bandung: Jemmars, 1984.

Rusmaini. Ilmu Pendidikan. Palembang: Grafindo Telindo Press, 2014 